\title{
Relations between peak snow accumulation and canopy density ${ }^{1}$
}

\author{
by Patrick Teti ${ }^{2}$
}

\begin{abstract}
Snow was monitored for five years in plots from which $30 \%$ of the timber had been previously removed in the form of group selection and in an unlogged control at a sub-alpine site in British Columbia. Average peak snow water equivalents (SWE) ranged from 38 to $52 \mathrm{~cm}$ and occurred between late March and mid-April. Canopy density was measured in circular areas of sky in 10-degree increments from the zenith to the horizon. The optimum parameter for explaining the variability of peak SWE was canopy density within a 60- to 80-degree-wide cone. Results suggest that where openings are 1 ha or less, peak SWE approached a locally consistent maximum value when canopy density approached zero. This improves our ability to predict the effects of group selection on snow accumulation in high elevation forests.
\end{abstract}

Key words: forest canopy, snow interception, snow accumulation, group selection

La quantité de neige a été mesurée pendant cinq ans dans des parcelles où $30 \%$ du bois avait été extrait sous forme de sélection de groupe d'arbres et dans des parcelles témoins non exploitées sur une station sub-alpine de la Colombie-britannique. Les quantités maximales équivalentes en eau de la neige ont varié de 38 à $52 \mathrm{~cm}$ et se sont produites entre la fin mars et la mi-avril. La densité du couvert forestier a été mesurée par des superficies circulaires du ciel augmentant par tranches de 10 degrés à partir du zénith jusqu'à l'horizon. Le paramètre optimal pour expliquer la variabilité de la quantité équivalente en eau maximale était la densité du couvert comparable à un cône de 60 à 80 degrés de largeur. Les résultats suggèrent que lorsque les ouvertures sont d'un hectare ou moins, la quantité équivalente en eau maximale s'approchait d'une valeur maximale localement constante lorsque la densité du couvert était proche de zéro. Ceci améliore notre capacité à prédire les effets de la sélection par groupe d'arbres sur l'accumulation de la neige dans les forêts de hautes altitudes.

Mots-clés : couvert forestier, interception de la neige, accumulation de la neige, sélection par groupe d'arbres

\section{Introduction}

High elevation forests in the Interior of British Columbia are cooler and much wetter than surrounding plateaus and valleys. They accumulate deep snowpacks through the winter and release it in a matter of weeks during the spring. The routed meltwater dominates the spring and summer hydrologic regimes of streams for great distances downstream. Springtime snowmelt and peak flows also affect slope stability, stream channel morphology, fish habitat, and public safety. Therefore, anything which affects snow accumulation and melt in high elevation forests can have significant local and downstream effects. High elevation forests in $\mathrm{BC}$ also provide critical habitat for mountain caribou (Rangifer tarandus) which are declining and at risk of extinction if current trends continue (Anonymous 2000). Deep, late-lying snow is a critical aspect of habitat and forest regeneration. For all of these reasons, it is useful to understand how timber harvesting in high elevation forests affects snow accumulation.

Group selection harvesting is being used in experimental and adaptive management trials in high elevation forests of $\mathrm{BC}$ as a tentative means of harvesting timber without seriously affecting mountain caribou. Researchers are studying the effects of group selection on snow, forest regeneration, and habitat for small mammals and birds as well as its effects on mountain caribou habitat (e.g., Soneff and Waterhouse 1997,

${ }^{1}$ Paper presented at "Mountain Forests: Conservation and Management," IUFRO Silviculture Conference, Vernon, British Columbia, Canada, July 28-August $1,2002$.

${ }^{2}$ Research Hydrologist, B.C. Ministry of Forests, \#200 - 640 Borland St., Williams Lake, B.C. V2G 4T1. E-mail: Pat.Teti@gems7.gov.bc.ca
Huggard 2002). The purposes of this paper are to investigate relationships between snow and canopy and to improve our ability to predict the effects of group selection silvicultural systems on peak snow accumulation.

\section{Previous Research}

Peak snow accumulation has been shown to increase after timber harvesting by many authors. Winkler (2001)

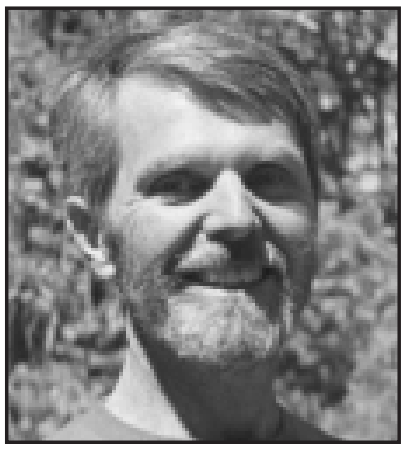

Patrick Teti reviewed the literature on the effects of 1-ha and larger openings on peak snow water equivalent. Her summary shows that peak SWE in harvested openings has been found to exceed that in stands of pine, fir, and spruce by a few percent to $98 \%$ and by less than $1 \mathrm{~cm}$ to $31 \mathrm{~cm}$ of water equivalent. The wide range of effects indicates that quantitative generalizations about snow in openings versus snow in the forest are subject to considerable uncertainty.

Some studies suggest that it may be feasible to develop a simple predictive model of snow accumulation in natural and partially logged forests. After reviewing published data representing conifer stands with a range of ages and species, Harestad and Bunnell (1981) suggested that peak SWE was a function of canopy density and maximum snowfall in openings. Moore and McCaughey (1997) found that canopy cover in a 30-degreewide field of view explained $51 \%$ to $74 \%$ of the variance in peak SWE in spruce- and fir-dominated plots ranging in age from 49 to 270 years. At sites representing a wide range of conifer 


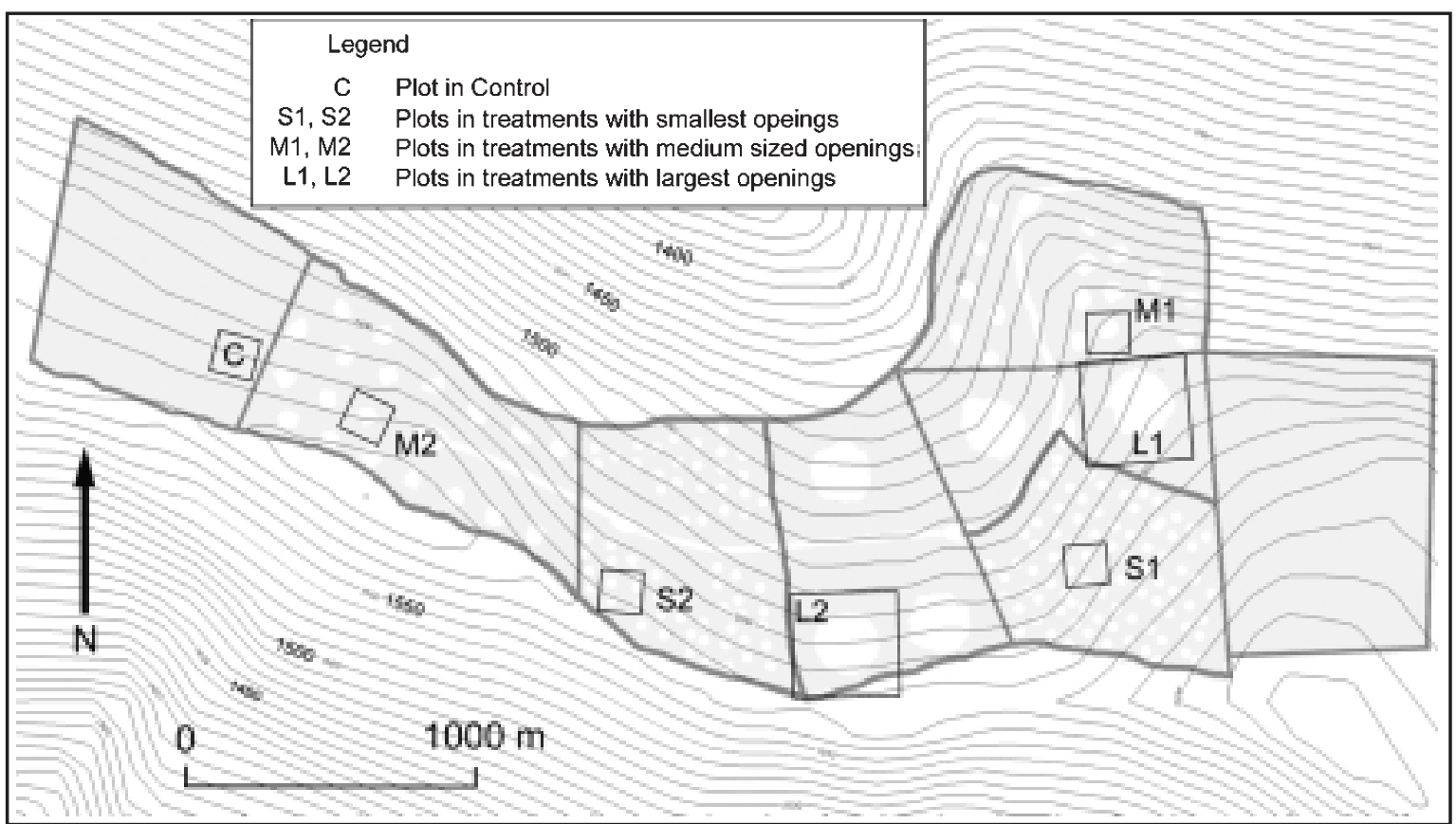

Fig. 1. Study area, treatment boundaries, snow plot locations, and 10-metre contour intervals.

stand ages, species, and stem densities, Winkler (2001) found that crown closure by moosehorn (approximately a 20-degreewide field of view centred on the zenith) explained more variance in peak SWE (26\% to $28 \%$ ) than any other parameter at the plot scale and that average crown closure by moosehorn explained almost as much of the variance (68\% to 84\%) between plots as the best parameter, which was average crown length (79\% to $86 \%$ ). Other researchers have documented relationships between canopy and snow interception processes in more detail and with better model success but their results are not directly comparable to seasonal peak SWE because they are for individual storms (McNay et al. 1988) and for weekly time steps (Hedstrom and Pomeroy 1998).

These studies show that canopy density can be an effective predictor of snow interception and peak SWE at the plot and stand scales. However, not all authors clearly defined the canopy density parameter that they used. Among those who described the parameter, a variety of canopy metrics and methods were used. Of those cited above, only Moore and McCaughey (1997) examined the effect of different fields of view (30 and 45 degrees) on the quality of the snow versus canopy relation.

\section{Study Area}

Research was carried out in the ESSFwc3 biogeoclimatic zone (Cariboo Variant of the wet, cold Engelmann Spruce - Subalpine Fir zone; Steen and Coupe 1997) at elevations between 1500 and 1600 metres. The unlogged forest consists of a multi-level, multi-age stand of mostly subalpine fir (Abies lasiocarpa) and Englemann spruce (Picea engelmannii) up to 290 years of age and 25 metres in height. The slope directions ranged from northwest to north-northeast with average gradients of $10 \%$ to $20 \%$.

\section{Methods}

A 119-ha study area was divided into eight units ranging in size from 11 to 19 ha as part of multidisciplinary study. Three different group selection treatments were applied to six treatment units and two units were left as controls. Treatments consisted of evenly repeated patterns of three different diameters of circular openings (20,40, and $113 \mathrm{~m}$ ), each with $30 \%$ volume removal. Opening sizes were selected to achieve multidisciplinary research objectives. There were two replicates of each of the three treatment types and they were harvested in the summer of 1992 and in the subsequent winter. Plots for undertaking snow surveys were established after harvesting in each of the three different treatments and in a control at locations shown in Fig. 1. Each snow plot spanned a representative subarea of the repeated group selection pattern as shown in Fig. 2. Forty measurement points (bamboo pole attached to steel rebar) were placed in each plot on a 5 by 8 grid using a predefined spacing from an arbitrary point of commencement.

Snow surveys were done with a Standard Federal Snow Sampler, which was always inserted into the snow $70 \mathrm{~cm}$ from the bamboo pole in a random direction in order to avoid measuring disturbed snow on subsequent visits and to reduce the bias associated with slightly non-random snow stake locations (i.e., rocky ground and trees). When a measurement point fell within a tree bole, zero snow was recorded. Snow depths and snow water equivalents (SWE) were measured in this way at each point six or seven times at approximately 10-day intervals in the spring of each year from 1994 through 1998. Optical canopy densities were measured in 2000 at all points in five of the seven plots by the following method. Digital images of the celestial hemisphere were made at each point with a Nikon Coolpix 990 camera and fisheye adapter (FC-E8). Maximum camera resolution yielded images with approximately 1400 pixels from edge to edge across the celestial hemisphere. Images were binarized utilizing colour information into sky and canopy pixels with Adobe Photoshop LE. Canopy densities were then calculated in vertical angle increments of 10 degrees using Scion Image. 


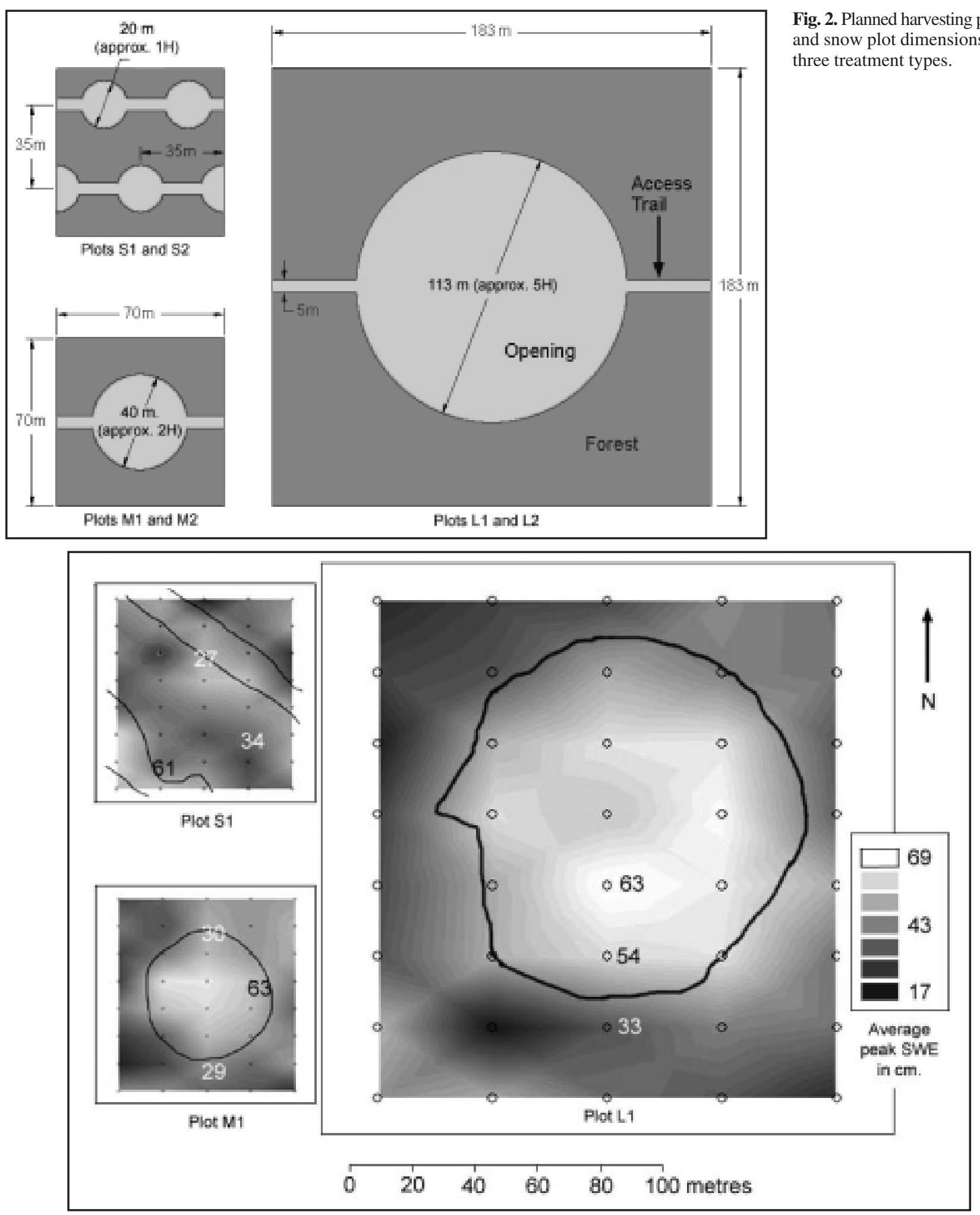

Fig. 3. Maps of snow measurement points, average peak SWE, and actual opening boundaries in three plots.

\section{Results}

For each snow survey plot, the highest average SWE in each year was taken to represent the plot's annual average maximum and the SWE at each point on that date was taken to represent each point's annual maximum. Annual maxima occurred between March $27^{\text {th }}$ and April $18^{\text {th }}$ during the five years of observation and plot averages ranged from 38 to $52 \mathrm{~cm}$. Fig. 3 shows maps of average peak SWE in one of each of the three different treatment types (S1, M1, and L1). Opening boundaries were mapped after logging and represent midpoints between stand- 


\begin{tabular}{|c|c|c|c|c|c|c|c|c|c|}
\hline \multirow[b]{2}{*}{ Plot } & \multirow[b]{2}{*}{$\begin{array}{c}\text { Opening } \\
\text { diameter }(\mathbf{m})\end{array}$} & \multirow[b]{2}{*}{$\begin{array}{c}\text { Actual \% } \\
\text { logged }\end{array}$} & \multicolumn{4}{|c|}{ Average Peak SWE (cm) } & \multicolumn{3}{|c|}{$\begin{array}{l}\text { Average Canopy Density } \\
\text { above } 60 \text { degrees }(\%)\end{array}$} \\
\hline & & & $\begin{array}{c}\text { Whole } \\
\text { plot }\end{array}$ & $\begin{array}{c}\text { Opening } \\
\text { Points } \\
\text { Only } \\
\end{array}$ & $\begin{array}{c}\text { Forest } \\
\text { Points } \\
\text { Only }\end{array}$ & $\begin{array}{l}\text { Opening } \\
\text { - Forest }\end{array}$ & $\begin{array}{c}\text { Whole } \\
\text { plot }\end{array}$ & $\begin{array}{c}\text { Opening } \\
\text { Points } \\
\text { Only } \\
\end{array}$ & $\begin{array}{c}\text { Forest } \\
\text { Points } \\
\text { Only }\end{array}$ \\
\hline S1 & 20 & 25 & 44.3 & 52.9 & 41.0 & 11.9 & 42 & 18 & 51 \\
\hline $\mathrm{S} 2$ & 20 & 34 & 47.2 & 55.5 & 45.1 & 10.4 & 45 & 14 & 53 \\
\hline M1 & 40 & 25 & 43.5 & 54.4 & 40.3 & 14.1 & & & \\
\hline M2 & 40 & 21 & 38.1 & 47.2 & 35.4 & 11.8 & 42 & 12 & 50 \\
\hline L1 & 113 & 28 & 42.2 & 54.8 & 36.8 & 17.9 & 39 & 2 & 55 \\
\hline L2 & 113 & 28 & 52.2 & 66.1 & 46.4 & 19.7 & & & \\
\hline $\mathrm{C}$ & NA & 0 & 42.3 & & 42.3 & & 51 & & 51 \\
\hline
\end{tabular}

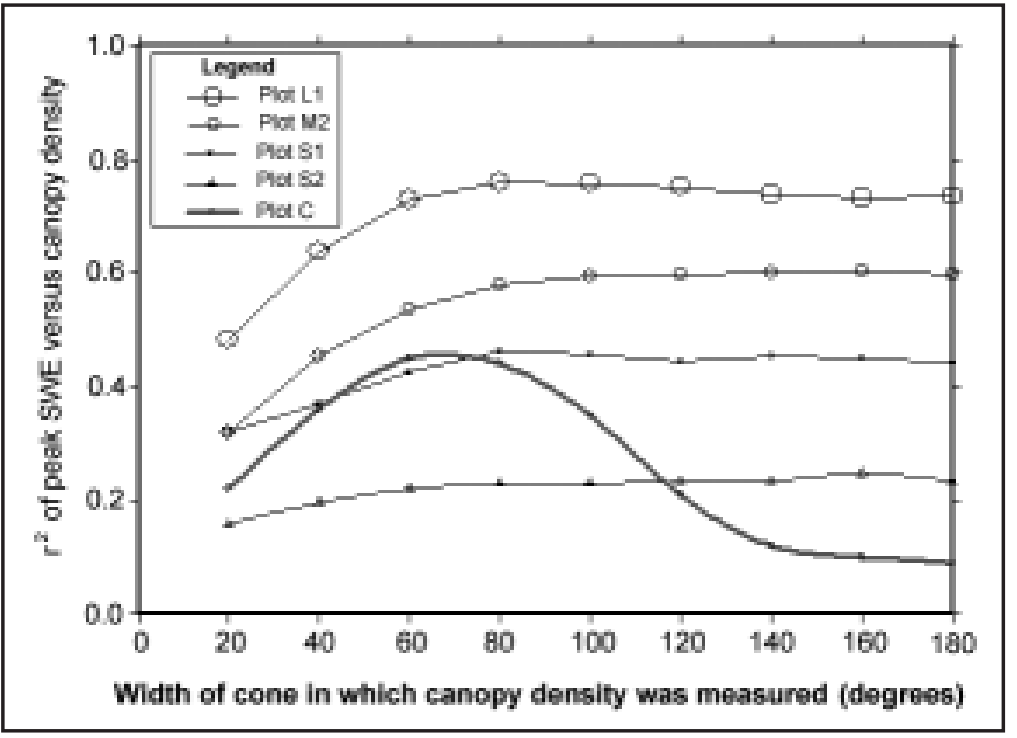

Fig. 4. Coefficients of determination versus angle of view in which canopy density was measured.

ing trees and stumps. Actual opening patterns within the snow plots deviated slightly from the plan, resulting in actual harvested portions of snow plots in treatment units ranging from $21 \%$ to $34 \%$. These and other data for each plot are summarized in Table 1. In all plots located in treatment units, average SWE at points in openings exceeded average SWE at points in the forest by 10.4 to $19.7 \mathrm{~cm}$.

Canopy photography allowed me to first investigate the role of angle of view on the relation between peak SWE and canopy density. In each snow survey plot for which I had fisheye photographs, I regressed average peak SWE at each point against canopy density in cones from 20 to 180 degrees wide in 20-degree increments. As shown in Fig. 4, the coefficients of determination increased most rapidly as canopy density was measured in cones increasing in width from 20 to 60 degrees. As canopy density was measured in wider cones, the coefficients of determination either decreased or increased by a modest amount. Canopy density in a 60-degree-wide cone was selected as the independent variable for subsequent analysis. These and other data are summarized by plot and by opening versus forest in Table 1. Because the overall percent areas harvested and average peak SWEs were similar between plots, the results were not well suited for comparing plot averages of peak SWE versus plot averages of canopy density.

Peak SWE versus canopy density relationships within plots are shown in Fig. 5. Boxes (a) through (e) of Fig. 5 show the inverse relationships between peak SWE and canopy density in all five plots. Y-intercepts were very similar $(56$ to $62 \mathrm{~cm})$ across all plots but were nearly identical (56.3 to 57.7) in the four plots located in partially harvested treatments. However, the regressions also had noteworthy differences, with slopes ranging from -20 to -39 and coefficients of determination from 0.22 to 0.73 . Regression lines for the five plots are superimposed in Fig. 5(f) for comparison.

\section{Discussion and Conclusions}

Bunnell and Vales (1990) suggested that researchers attempting to develop relations between overstory cover and factors such as snow interception should measure canopy in angles of view appropriate to the factor being studied. However, this has not been previously addressed other than by Moore and McCaughey (1997) who compared 30- and 45-degree-wide fields of view. In the stands I studied, 60- to 80-degree-wide fields of view provided the best snow versus canopy relationships. Peak SWE approached approximately the same value as this canopy density parameter approached zero in all plots. These findings support the concept presented by Harestad and Bunnell (1981) in which snow accumulation is highest in openings and decreases in the forest in proportion to canopy density. It also clarifies canopy density for purposes of snow interception. In the plots I studied, a refinement of Harestad and Bunnell's conceptual model would be that snow falls along trajectories 


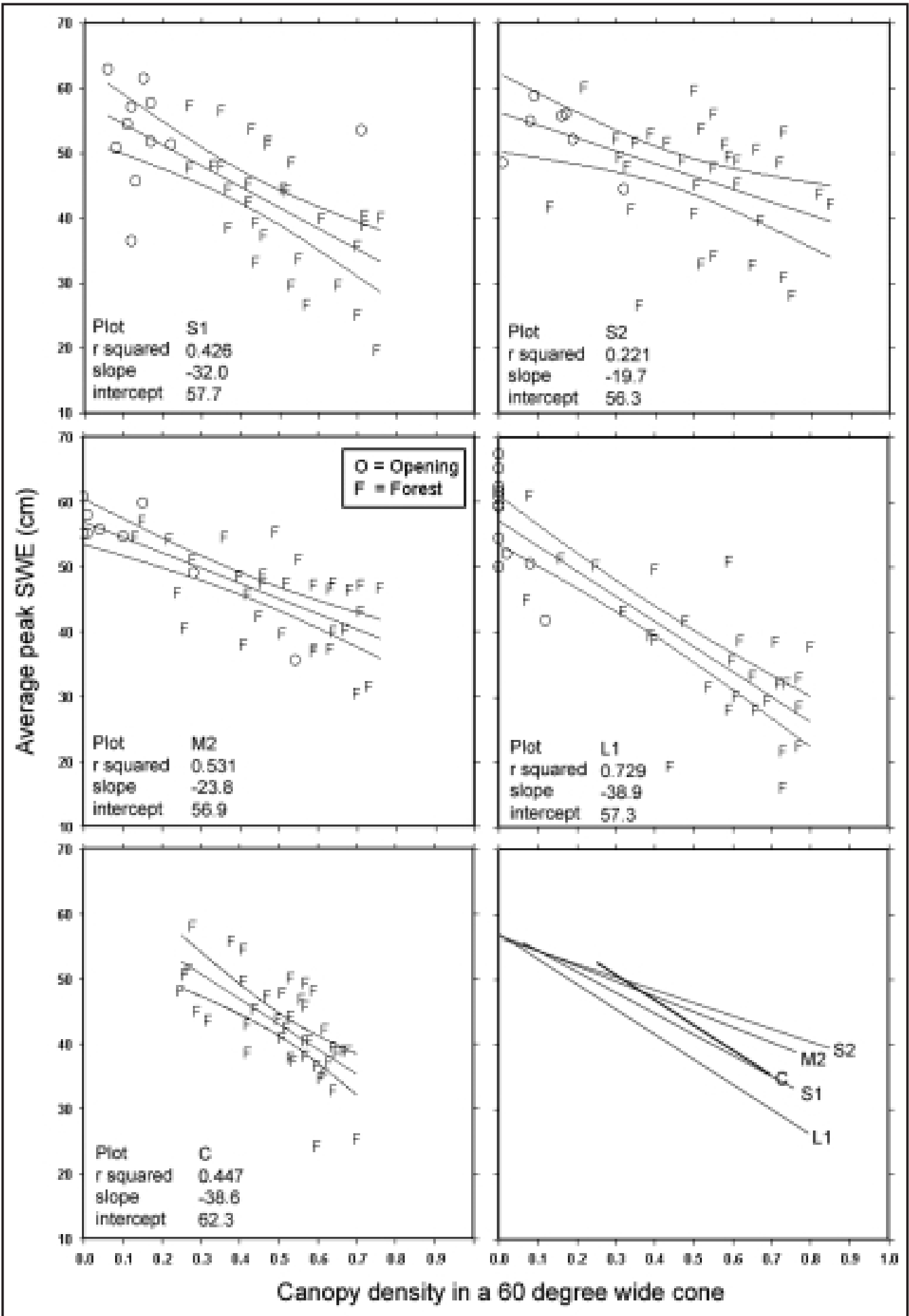

Fig. 5. Scattergrams of peak SWE versus canopy density in five snow plots showing regressions with $95 \%$ confidence limits.

that are up to 40 degrees from the vertical and a portion of falling snow is subject to interception loss after contacting canopy along those trajectories. However, some aspects of the observed peak snow versus canopy density relationships require further explanation.

Canopy density explained less than half of the variance in peak SWE in plots located in the control and in plots with the smallest openings. This may be partly due to edge effects which would be greater in plots $\mathrm{S} 1, \mathrm{~S} 2$, and $\mathrm{C}$ because snow stakes in those plots tended to be closer to the nearest trees than snow stakes in plots M2 or L1 due to the smaller opening dimensions. One process that occurs only very close to trees is the downward shedding of snow by the crowns of individual trees thus decreasing snow accumulation inside driplines and increasing it outside of driplines. This source of error would be smallest in plot L1 and this is consistent with that plot having the highest r-squared between peak SWE and canopy density. The high variability of peak SWE near trees in all plots 
also supports interception loss over snow redistribution from canopies to openings as the process causing differences between openings and forest because large lateral displacement of snow should tend to reduce the variability that occurs around tree driplines.

Slopes of the SWE versus canopy density relationships indicated that the canopy in plots L1 and S1 caused nearly twice as much interception loss per unit of canopy density as the canopy in plots $\mathrm{S} 2$ and M2. It is possible that the northwesterly aspects of plots L1 and S1 in combination with afternoon occurrences of daily maximum air temperatures could have resulted in more frequent temperatures above freezing during the snow accumulation season and therefore more snow adhesion to and ablation from the canopies of these plots than in the two plots with northeasterly aspects. I plan to further analyze the data to look for directional effects of canopy that might be associated with preferred wind directions during snowfall and with radiation-induced ablation during winter.

This experiment lacked pre-treatment observations and had only two replicates of each of three treatment types so it did not allow a direct test of the overall effects of the three treatment types on peak SWE. However, it provided insight to interactions between snow and canopy within plots which, if confirmed at larger scales and over a wider range of conditions, will improve our ability to predict the effects of group selection on peak snow accumulation.

\section{Acknowledgements}

This multidisciplinary silvicultural system experiment was conceived largely by my colleague, Harold Armleder and was possible only with the interest and co-operation of Weldwood of Canada Ltd. Financial support was provided by FRDA II and Forest Renewal B.C. Ellie Veninga carried out most of the snow surveys and I thank my keen summer field assistants for their help. Lastly, I would like to thank the reviewers for their helpful comments.

\section{References}

Anonymous. 2000. Mountain Caribou Strategy. Prepared by the Cariboo-Chilcotin Land Use Plan Caribou Strategy Committee. 73 p. + Appendices. Downloaded from www.gov.bc.ca/wlap/.

Bunnell, F.L. and D.J. Vales. 1990. Comparison of methods for estimating forest overstory cover: differences among techniques. Can. J. For. Res. 20: 101-107.

Harestad, A.S. and F.L. Bunnell. 1981. Prediction of snow-water equivalents in coniferous forests. Can. J. For. Res. 11: 854-857.

Hedstrom, N.R. and J.W. Pomeroy. 1998. Measurements and Modelling of Snow Interception in the Boreal Forest. Hydrological Processes 12: 1611-1625.

Huggard, D.J. 2002. Comparing clearcutting and alternatives in a high-elevation forest: early results from Sicamous Creek. Kamloops Forest Region Extension Note \#63. 10 p.

McNay, S.R., L.D. Peterson and J.B. Nyberg. 1988. The influence of forest stand characteristics on snow interception in the coastal forests of British Columbia. Can. J. For. Res. 18: 566-573.

Moore, C.A. and W.W. McCaughey. 1997. Snow accumulation under various forest stand densities at Tenderfoot Creek Experimental Forest, Montana, USA. In Proceedings of Western Snow Conference, May 5-8, 1997, Banff, Alberta. pp. 42-51.

Soneff, K. and M. Waterhouse. 1997. Progress Report on Group Selection Systems for High Elevation Forests. Cariboo Forest Region Extension Note \#22. 8 p.

Steen, O.A. and R.A. Coupe. 1997. A field guide to forest site identification and interpretation for the Cariboo Forest Region. B.C. Min. For., Victoria, B.C. Land Management Handbook No. 39.

Winkler, R.D. 2001. The Effects of Forest Structure on Snow Accumulation and Melt in South-Central British Columbia. PhD. Thesis, Faculty of Forestry, University of British Columbia, Vancouver, B.C. $151 \mathrm{p}$. 